\title{
Safety and effectiveness of laparoscopic Y-en-Roux gastric bypass surgery in obese elderly patients ${ }^{1}$
}

Marcelo Protásio dos Santos' (D), José Eduardo Gonçalves" (D), André Akira Ramos Takahashi"l' (D) , Bruno Barros Britto ${ }^{\mathrm{V}}$ (D) , Fernando Bray Beraldov (D) , Jaques Waisberg ${ }^{\mathrm{VI}}$ (D) , Luciana Kase Tanno ${ }^{\mathrm{VII}}$

I MD, MsC. Department of Surgery, Hospital do Servidor Público Estadual (IAMSPE), Sao Paulo-SP, Brazil. Design of the study, interpretation of data, manuscript preparation.

" PhD, Department of Surgery, IAMSPE, Sao Paulo-SP, Brazil. Interpretation of data.

III MD, Department of Surgery, Faculdade de Medicina do ABC, Santo Andre-SP, Brazil. Manuscript preparation, critical revision.

IV MD, Department of Surgery, Faculdade de Medicina Tiradentes, Aracaju-SE, Brazil. Interpretation of data, manuscript preparation.

$\checkmark$ MD, Department of Surgery, IAMSPE, Sao Paulo-SP, Brazil. Acquisition and interpretation of data.

VI PhD, Department of Surgery, IAMSPE, Sao Paulo-SP, and Department of Surgery, Faculdade de Medicina do ABC, Santo Andre-SP, Brazil. Design of the study, interpretation of data, manuscript preparation, critical revision.

VII PhD, Division of Allergy, Department of Pulmonology, Hôpital Arnaud de Villeneuve, University Hospital of Montpellier, Paris, France. Analysis of data, manuscript preparation, critical revision.

\begin{abstract}
Purpose: To analyze, in aged obese patients, the weight loss, comorbidity control, and safety postoperative complications of bariatric surgery by Roux-en-Y gastric bypass technique.

Methods: Twenty-seven patients who underwent laparoscopic weight-reducing gastroplasty with Roux-en-Y gastric bypass to treat obesity were included. All patients were $\geq 60$ years old at the time of surgery. The Wilcoxon test was used for statistical analysis, and a $p$-value $\leq 0.05$ it was considered significant.

Results: Ten $(90.9 \%)$ patients with dyslipidemia were cured $(p<0.001)$. Nine $(81.8 \%)$ patients with type 2 diabetes mellitus had total improvement and $2(18.2 \%)$ had partial improvement $(p=0.003)$. In 23 patients with systemic arterial hypertension, 9 (39.1\%) achieved total improvement and 14 (60.9\%) partial improvement $(p=0.140)$. Five $(71.4 \%)$ patients with obstructive sleep apnea syndrome were cured $(p=<0.001)$. For other comorbidities, no partial improvement or cure was shown.

Conclusions: Roux-en-Y gastric bypass surgery in obese elderly patients can be performed safely and with low morbidity and mortality rates. The benefits of weight loss and reduced comorbidities are promising and like those of the younger population.
\end{abstract}

Key words: Anastomosis, Roux-en-Y. Bariatric Surgery. Aged. 


\section{- Introduction}

Obesity, given the significant associated morbidity and mortality rates, is considered a worldwide epidemic with high costs for society and health systems ${ }^{1}$. In 2014, the World Health Organization (WHO) estimated that approximately 1.9 billion adults worldwide were overweight and at least 600 million were obese ${ }^{2}$. The major medical concern regarding obesity is the large number of associated diseases, especially cardiovascular disease, diabetes, and malignant neoplasms ${ }^{3}$. Several long-term epidemiological studies have been able to demonstrate this strong association, as well as evidence of reduced quality of life and increased mortality in these patients ${ }^{4-6}$.

Although clinical treatment shows good results, the Roux-in-Y gastric bypass (RYGB) procedure is considered the gold standard for weight loss, and it has been the most widely performed bariatric procedure worldwide. Nevertheless, nowadays, vertical gastrectomy is considered the most frequently performed operation ${ }^{7}$. The gastric pouch has considerably smaller volume $(60$ $\mathrm{ml}$ ), which facilitates the lower consumption of food and calories. In addition, there is less assimilation of calories and nutrients.

The premature existence of ingested foods that pass into the distal small intestine may stimulate secretion of substances such as glucagon-1 peptide, leading to improved insulin sensitivity, increased insulin production and decreased resistance to insulin. This improvement in insulin sensitivity has proven to be an independent factor of weight loss ${ }^{8}$. Due to duodenum bypass, RYGB has the potential to cause vitamin deficiencies, as well as deficiencies in minerals such as iron, copper, selenium, zinc, calcium and phosphorus 9 .

The elderly population represents a growing share of the world's population. It is estimated that $8 \%$ of people worldwide are over 75 , and by 2025 , this percentage is estimated to reach $10 \%{ }^{10}$. The population over 60 years old already corresponds to $23 \%$ of all surgical procedures performed in the world. However, the number of elderly people undergoing surgery is increasing more than the elderly in the general population ${ }^{11}$. A significant portion of elderly patients present higher risks of morbidity and mortality in emergency and even elective procedures when compared to patients of other age groups ${ }^{12}$.

The prevalence of obesity among the elderly is increasing, and it is estimated in $17.9 \%$ on 65 years old $^{13}$. Increased waist circumference was present in $47.6 \%$ of people ${ }^{13}$. The sarcopenic obesity, defined as the coexistence of sarcopenia and obesity, significantly affects the exercise of daily activities, affecting the quality of life and even the number of hospitalizations ${ }^{14}$.
In addition, another problem of immobility and high body mass index in the elderly is the increased incidence of pressure ulcers. A retrospective cohort study found that hospitalized and intensive care patients with grade III obesity (BMI $\geq 40 \mathrm{~kg} / \mathrm{m}^{2}$ ) had significantly more pressure ulcers than other patients, as well as a higher mortality rate ${ }^{15}$.

As a result of this scenario, surgical procedures to treat obesity in the elderly are increasing and represent about $10 \%$ of the total bariatric surgeries performed in academic centers ${ }^{16,17}$. The majority of the studies advocates in favor of the safety and efficiency of bariatric surgery; however, a deeper knowledge is needed to examine the outcome in elderly patients. The perioperative morbidity and mortality in elderly patients are the central concern for bariatric surgery in this population. This issue associated with the lack of studies, contributes for medical care centers to deny bariatric surgery coverage to patients over the age of 60 years ${ }^{16}$.

The approach to combating obesity in the geriatric population still lacks solid information and wellestablished methods because it is a recent research area and many doubts are still observed in this practice ${ }^{18}$. Thus, due to the increase in obese elderly and the lack of consensus on the efficacy and safety of bariatric surgery for these patients, we consider it important to analyze the results of gastric bypass surgery in $\geq 60$ year-old obese patients.

The aim of the present study was to analyze the results of comorbidity control before and after 2 years of laparoscopic RYGB in $\geq 60$ year-old obese patients and to identify possible postoperative complications of this procedure in this population.

\section{- Methods}

The research protocol for this study was approved by the Research Ethics Committee of the institution.

This retrospective study was performed with adult patients of both genders who underwent laparoscopic RYGB. All surgeries were performed using Roux-en-Y gastroplasty with a $60 \mathrm{~cm}$ long biliopancreatic loop; the length of the alimentary loop was $120 \mathrm{~cm}$ and a $3-4 \mathrm{~cm}$ gastric pouch was created. One of the patients also received a non-adjustable silicone ring around the gastric pouch. All surgical procedures were performed at the Department of Surgery (Gastrointestinal Surgery Division) of the Hospital do Servidor Público Estadual. Clinical and laboratory data were obtained from medical records of patients that underwent an operation between January 2011 and January 2014. 
Inclusion criteria for patients in this study were age $\geq$ 60 years, body mass index $(\mathrm{BMI}) \geq 40 \mathrm{~kg} / \mathrm{m}^{2}$ regardless of the presence or absence of comorbidities, BMI $\geq 35 \mathrm{~kg} / \mathrm{m}^{2}$ associated with one or more comorbidities, and acceptance of the consent form after all the benefits and risks offered by the operation were clarified. The exclusion criteria adopted were patients submitted to other modalities of bariatric operations or who underwent the same surgical procedure with an open approach.

We studied 25 (92.6\%) women and 2 (7.4\%) men, regardless of ethnicity. The average age of the patients was $63.1 \pm 3.6$ years ( 60 to 75 years old).

All patients had grade II or III obesity according to WHO criteria, whether or not it was associated with one or more of the following comorbidities: arthropathy, asthma, depression, dyslipidemia (DLP), type 2 diabetes mellitus (T2DM), gastroesophageal reflux disease (GERD), systemic arterial hypertension (SAH), hypothyroidism, and obstructive sleep apnea syndrome (OSAS) ${ }^{2}$.

The absence of the need for medication for postoperative comorbidity control was considered a cure, and the need for medication at a lower dose than the preoperative dose was considered partial comorbidity control.

The quantitative variables analyzed were age, length of hospital stay, maximum patient weight, preoperative weight, weight after 24 months of operation, percentage of excess weight loss (\%EWL), maximum patient $\mathrm{BMI}$, preoperative BMI, BMI 24 months after surgery, number of comorbidities, number of preoperative medications, and medications used to control comorbidities 24 months after surgery.

Statistical analysis used mean with standard deviation, median and percentages. The nonparametric Wilcoxon test and confidence intervals were employed. The significance level adopted was 0.05 (5\%).

\section{- Results}

The average length of hospital stay was $5.67 \pm 1.73$ days ( 4 to 12 days). The average maximum weight was $116.6 \mathrm{~kg}$ $\pm 18.2(93 \mathrm{~kg}$ to $180 \mathrm{~kg}$ ) and the average weight after 24 months of follow-up was $73.1 \mathrm{~kg} \pm 11.7$ (50 kg to $100 \mathrm{~kg}$ ). The mean \%EWL was $74.6 \% \pm 22.2$ (31.8\% to $135.6 \%$ ) (Table 1 ).

The average of maximum BMI was $46.6 \mathrm{~kg} / \mathrm{m}^{2} \pm 5.5$ $\left(38 \mathrm{~kg} / \mathrm{m}^{2}\right.$ to $60 \mathrm{~kg} / \mathrm{m}^{2}$ ) and the mean preoperative BMI was $42.0 \mathrm{~kg} / \mathrm{m}^{2} \pm 4.3\left(33.8 \mathrm{~kg} / \mathrm{m}^{2}\right.$ to $\left.54 \mathrm{~kg} / \mathrm{m}^{2}\right)$. After 24 months of evaluation, the mean BMI was $28.3 \mathrm{~kg} / \mathrm{m}^{2} \pm$ $3.3\left(22 \mathrm{~kg} / \mathrm{m}^{2}\right.$ to $\left.33 \mathrm{~kg} / \mathrm{m}^{2}\right)$ (Table 1 ).

Before surgery, the patients used five medications per day on average to control obesity-associated comorbidities (T2DM, SAH, and DLP). After 24 months, there was a reduction to three medications on average per day per patient (Table 1).

Table 1 - Description of quantitative variables of elderly patients undergoing laparoscopic Roux-en-Y gastric bypass.

\begin{tabular}{lccc}
\hline Variables & Mean (Min-Max) & Median & SD \\
\hline Age (years) & $62(60-75)$ & 62 & 3.6 \\
Days of hospitalization & $5.67(4-12)$ & 5 & 1.73 \\
Maximum weight $(\mathrm{kg})$ & $116.6(93-180)$ & 110 & 18.2 \\
Preoperative weight $(\mathrm{kg})$ & $104.3(83-170)$ & 103 & 16.6 \\
Weight after 24 months $(\mathrm{kg})$ & $73.1(50-100)$ & 70 & 11.7 \\
\%EWL after 24 months & $74.6 \%(31.8-135.6)$ & 22.2 \\
Maximum BMI & $46.6(38-60)$ & 46 & 5.5 \\
Preoperative BMI & $42.0(33.8-54)$ & 43.0 & 4.3 \\
BMI after 24 months & $28.3(22-33)$ & 29 & 3.3 \\
No. of comorbidities & $2(0-5)$ & 2 & 1.33 \\
No. of preoperative medications & $6(0-15)$ & 6 & 3.93 \\
No. of medications after 24 months & $3(0-10)$ & 3 & 1.84 \\
\hline
\end{tabular}

Min. = minimum; Max. = maximum; SD = standard deviation; $\% \mathrm{EWL}=\%$ of excess weight loss; $\mathrm{BMI}=$ body mass index.

Theaverage number of obesity-associated comorbidities per patient was 2 . Of the 27 patients, $25(92.6 \%)$ had one or more obesity-related diseases. In this group of patients, the distribution of comorbidities is shown in Table 2. 
Table 2 - Distribution of comorbidities in elderly patients before and after undergoing laparoscopic Roux-en-Y gastric bypass.

\begin{tabular}{|c|c|c|c|}
\hline Comorbidities & $\begin{array}{c}\text { Preoperative period } \\
\text { N (\%) }\end{array}$ & $\begin{array}{c}\text { Postoperative period } \\
\text { N }(\%)\end{array}$ & P-value \\
\hline Arthropathy & $2(7.4 \%)$ & $1(3.7 \%)$ & 0.2 (N.S.) \\
\hline Asthma & $2(7.4 \%)$ & $1(3.7 \%)$ & 0.2 (N.S.) \\
\hline Depression & $1(3.7 \%)$ & 0 & 0.1 (N.S.) \\
\hline Dyslipidemia (DLP) & $11(40.7 \%)$ & $1(3.7 \%)$ & $<0.001 *$ \\
\hline Type 2 diabetes mellitus (T2DM) & $11(40.7 \%)$ & $9(33.3 \%)$ & $0.003 *$ \\
\hline Gastroesophageal reflux disease (GERD) & $1(3.7 \%)$ & 0 & 0.1 (N.S.) \\
\hline Systemic arterial hypertension (SAH) & $23(85.2 \%)$ & $9(33.3 \%)$ & 0.14 (N.S.) \\
\hline Hypothyroidism & $5(18.5 \%)$ & $2(7.4 \%)$ & 0.09 (N.S.) \\
\hline $\begin{array}{l}\text { Obstructive sleep apnea syndrome } \\
\text { (OSAS) }\end{array}$ & $7(25.9 \%)$ & $2(7.4 \%)$ & $<0.001 *$ \\
\hline
\end{tabular}

Wilcoxon test; ${ }^{*}=$ Significant; N.S. = Not significant.

Regarding comorbidities, of the 11 patients who presented with DLP, 10 (90.9\%) were cured ( $p<0.001)$. Of the 11 patients with T2DM, $9(81.8 \%)$ had total improvement and 2 (18.2\%) had partial improvement $(p=0.003)$. Concerning the 23 patients with $\mathrm{SAH}, 9$ (39.1\%) achieved total improvement $(p=0.140)$ and 14 (60.9\%) achieved partial improvement. Regarding OSAS, of the $7(28.0 \%)$ patients who presented this comorbidity before the operation, in 2 (8.0\%), OSAS remained after 24 months ( $p=<0.001$ ). For other comorbidities, no partial improvement or cure was shown.

Regarding the operative complications, it was observed that among the 27 patients in the study, 1 (3.7\%) had incisional hernia, 1 (3.7\%) developed surgical wound infection, and 5 (18.5\%) had other postoperative complications: 2 hypertensive crises, 2 bronchospasms and 1 atrial fibrillation with high ventricular response. At long-term follow-up, 1 patient presented solids dysphagia after 2 years with resolution after ring removal surgery. There were no deaths in this series.

\section{- Discussion}

The safety and efficacy of weight loss surgical procedures in the elderly is still controversial. Sugerman et $a .^{19}$ evaluated 850 elderly patients undergoing RYGB and indicated an operative mortality rate of $0.6 \%$ and morbidity of $5.6 \%$. The authors concluded that gastric bypass is a safe procedure in the elderly population due to low morbidity and mortality rates ${ }^{20}$. In the present study, there was no mortality, while the morbidity index was $29.6 \%$. Yoon et al. ${ }^{21}$ compared the outcomes of RYGB and vertical gastrectomy among populations $<60$ years and $\geq 60$ years of age and found no significant differences between the two populations regarding unfavorable outcomes. Postoperative complication rates among the population $<60$ years and $\geq 60$ years were, respectively, $2.5 \%$ and $5 \%$. Mean operative time was slightly longer in patients $\geq 60$ years $(210$ minutes vs. 229 minutes) and readmissions at 30 days occurred more frequently in the $\geq 60$ year-old group $(2.5 \%$ vs. $12.5 \%)$. However, the reasons for hospital readmissions in any of the groups were not detailed in this study ${ }^{21}$. In the present series, no hospital readmissions were recorded within 30 days after the surgical procedure.

Santo et al. ${ }^{22}$ evaluated 538 patients undergoing RYGB and found that the most frequent complications were surgical site infection (3.2\%), bleeding (2.6\%), and intestinal obstruction (1.1\%). The main clinical complication was pulmonary thromboembolism, found in $3(0.55 \%)$ patients. The total mortality rate of the study was $0.55 \%$ and was related to the presence of pulmonary thromboembolism and age $>65$ years. Trieu et al. ${ }^{23}$ noted that the most frequent early complications in patients $>60$ years of age were anastomotic dehiscence (2.2\%), bleeding (1.1\%), pulmonary thromboembolism (1.1\%), pneumonia $(1.1 \%)$, and atrial fibrillation (1.1\%). Late complications included gastrojejunal anastomosis stenosis (8.6\%), peptic ulcers $(3.2 \%)$, intestinal obstruction (1.1\%), internal hernias $(1.1 \%)$, and abdominal wall hernias (1.1\%). The authors did not report deaths in their clinical registries. Pajecki et al. ${ }^{24}$ in a study with morbidity and mortality results of elderly patients undergoing RYGB, had similar follow-ups to the previously mentioned studies, except that the mortality rate was $4.3 \%$ ( 2 patients), one death being caused by pulmonary thromboembolism and the other due to sepsis resulting 
from surgical wound infection. The researchers concluded that pulmonary thromboembolism and age above 65 years are predictors of mortality.

Older age is a predictor of increased length of hospital stay, although there is no significant increase in mortality. This has been shown in studies that found individuals over 65 to be most likely to require prolonged hospitalization ${ }^{25,26}$. Robert et al. ${ }^{27}$ revealed that the length of hospital stay after gastric bypass was similar in age groups $<40$ years, $40-55$ years, and $>60$ years. Following the present clinical registry, there was an average length of hospital stay of 5.67 days, with a minimum of 4 days and a maximum of 12 days. It is important to mention that during the period of the operations, the standardized hospitalization time was 4 days for patients undergoing gastroplasty, regardless of age.

Regarding \%EWL as a result of RYGB, studies point to the effectiveness of this technique in the elderly. Sugerman et $a .^{19}$, in a study of 80 patients aged between 60 and 66 years, weighing between 110 and $154 \mathrm{~kg}$ and with BMI between 42 and $56 \mathrm{~kg} / \mathrm{m}^{2}$, followed these patients for 5 years. After 1 year, patients had weight loss between 27 and $49 \mathrm{~kg}$ and a reduction in BMI to 27 to $43 \mathrm{~kg} / \mathrm{m}^{2}$. Pajecki et al. ${ }^{24}$ found that \%EWL was $71.8 \%$, similar to the results of the present study, in which an average \%EWL of $74.6 \%$ was obtained after 24 months.

Zaveri et al. $^{28}$ analyzed 57 patients aged $\geq 70$ years undergoing various modalities of bariatric surgery and followed them for 18 months. The authors compared the results of laparoscopic gastric band (24 patients), RYGB (14 patients), and duodenal switch (15 patients). The results obtained of \%EWL of BMI lost at the end of follow-up were $37.2 \%$ for gastric band, $88.4 \%$ for gastric bypass and $100.6 \%$ for duodenal switch ${ }^{28}$. Huang et al. ${ }^{29}$ observed that after performing RYGB, \%EWL was $65 \%$ in elderly patients. Abbas et al. ${ }^{30}$ obtained similar results because the mean \%EWL after 12 months of RYGB in patients with a mean age of 63.4 years was $65.2 \%$.

Gray et $a .^{31}$ in a retrospective study, analyzed weight loss in 69 elderly patients who underwent laparoscopic RYGB and obtained a percentage of total weight reduction of $23.9 \pm 9.3 \%$. These authors found that the percentage of weight loss after 3 years of gastric bypass in the elderly was lower than in young adults $(27.5 \pm$ $8.6 \%$ vs. $31.8 \pm 12.1 \%)$, as well as a reduction in $\mathrm{BMI}$ (12.7 \pm 4.9 vs. $15.2 \pm 6.2$ ). In the present clinical registry, a reduction in the mean BMI after 24 months of $13.7 \mathrm{~kg} /$ $\mathrm{m}^{2}$ (from $42 \mathrm{~kg} / \mathrm{m}^{2}$ to $28.3 \mathrm{~kg} / \mathrm{m}^{2}$ ) was observed, which was similar to the results of the study by Thereaux et al. ${ }^{32}$ Although considered effective in this population, results of RYGB in the elderly still diverge in terms of the effectiveness of weight loss.
Regarding the improvement or resolution of comorbidities, Zaveri et al. $^{28}$ showed that in $83.3 \%$ of patients over 70 years undergoing RYGB, there was a resolution of T2DM in $60 \%$ of cases, of OSAS in $65 \%$ of cases, of $\mathrm{SAH}$ in $50 \%$ of cases and of GERD in $50 \%$ of cases.

In the present study, $81.8 \%$ of patients had achieved T2DM improvement without the need for medication to control the glycemic level. Regarding hypertension, we obtained a resolution percentage of $39.1 \%$ and a reduction of $84.6 \%$ of OSAS. Pajecki et al. ${ }^{24}$ studied patients aged $\geq 60$ years who underwent RYGB and were followed for 39 months. The authors observed an improvement in comorbidities such as T2DM, SAH, DLP, and GERD ${ }^{31}$. In $23 \%$ of patients there was partial improvement of T2DM, while in 77\%, total control of these comorbidities was achieved. Regarding $\mathrm{SAH}$, in $26 \%$ of the cases, there was control with medication reduction, while in $30 \%$ the control was obtained without medication. The mean glycated hemoglobin of these patients decreased from $6.73 \%$ to $5.7 \%$. In the lipid profile, there was a significant increase in $\mathrm{HDL}$, a slight reduction in LDL, and a strong reduction in triglycerides. Ramirez et al. $^{33}$ showed reduced use of antidiabetic drugs in $40 \%$ of patients, complete resolution of T2DM in $33 \%$ of cases, and decreased use of medications for SAH (56\%), DLP (54\%), and degenerative knee disease $(50 \%)$. In the present study, there was a reduction of $47.9 \%$ in the use of medications to control comorbidities after 24 months (from 5.33 to 3.07 medications) and an improvement in DLP in $90.9 \%$ of patients.

The National Hospital Discharge Survey and the National Inpatient Survey observed about 25,000 bariatric surgeries, with $3.2 \%$ mortality in the elderly compared with $0.2-0.7 \%$ in other age groups ${ }^{34}$. Nelson et al. ${ }^{35}$ analyzed 25 patients $\geq 65$ years and showed $4 \%$ mortality and total complication rate in $20 \%$ of the cases. Pajecki et al. ${ }^{24}$ showed favorable results regarding weight loss and control of comorbidities in the elderly, and other studies showed adequate results of bariatric surgery in relation to weight loss and control of T2DM and hypertension in the elderly ${ }^{19,28}$.

\section{- Conclusions}

We conclude that laparoscopic RYGB is an effective method for controlling T2DM, DLP, and OSAS in obese elderly individuals ( $\geq 60$ years) in the first 24 months of postoperative follow-up. In addition, it has been shown to be a safe procedure with low rates of minor complications that often do not require surgical intervention in this population. However, further studies with a larger sample of people involved are needed to ratify the results obtained in the present series. 


\section{- References}

1. Crook MA, Sriram K. Bariatric surgery may not achieve intended outcomes in all patients. Nutrition. 2015;31(9):1182-3. doi: 10.1016/j.nut.2015.01.011.

2. World Health Organization. Obesity and overweight. Available from: https://www.who.int/news-room/factsheets/detail/obesity-and-overweight.

3. Nassif PA, Malafaia O, Ribas Filho JM, Czeczko NG, Garcia $\mathrm{RF}$, Ariede BL. When and why operate elderly obese. ABCD Arq Bras Cir Dig. 2015;28(Suppl.1):84-5. doi: 10.1590/ S0102-6720201500S100022.

4. Calle EE, Rodriguez C, Walker-Thurmond K, Thun MJ. Overweight, obesity, and mortality from cancer in a prospectively studied cohort of U.S. adults. N Engl J Med. 2003;348(17):1625-38. doi: 10.1056/NEJMoa021423.

5. Calle EE, Thun MJ, Petrelli JM, Rodriguez C, Heath CW Jr. Body-mass index and mortality in a propective cohort of U.S. adults. N Engl J Med. 1999;341(15):1097-105. doi: 10.1056/NEJM199910073411501.

6. Murphy NF, Maclntyre K, Stewart S, Hart CL, Hole D, McMurray JJV. Long-term cardiovascular consequences of obesity: 20-years follow-up of more than 15000 middle-aged men and women (the Renfrew-Paisley study). Eur Heart J. 2006;27(1):96-106. doi: 10.1093/ eurheartj/ehi506.

7. Ponce J, Nguyen NT, Hutter $M$, Sudan $R$, Morton JM. American Society for Metabolic and Bariatric Surgery estimation of bariatric surgery procedures in the United States, 2011-2014. Surg Obes Relat Dis. 2015;11(6):1199-200. doi: 10.1016/j. soard.2016.08.488.

8. Kumar R, Lieske JC, Collazo-Clavell ML, Sarr MG, Olson ER, Vrtiska TJ, Bergstralh EJ, Li X. Fat malabsorption and increased intestinal oxalate absorption are common after Roux-en-Y gastric bypass surgery. Surgery. 2011;149(5):654-61. doi: 10.1016/j.surg.2010.11.015.

9. Buchwald $H$, Avidor $Y$, Brachwald $E$, Jensen $M D$, Pories $W$, Fahrbach K, Schoelles K. Bariatric surgery: a systematic review and meta-analysis. JAMA. 2004;292(14):1724-37. doi: 10.1001/jama.292.14.1724.

10. National Statistics. Estimates of the very old (including centenarians): EnglandandWales, and United Kingdom, 2002 to 2014. Available from: https://www.ons.gov.uk/people populationandcommunity/birthsdeathsandmarriages/ ageing/bulletins/estimatesoftheveryoldincluding centenarians/2015-09-30.

11. Etzioni DA, Liu JH, Maggard MA, Ko CY. The aging population and its impact on the surgery workforce. Ann Surg. 2003;238(2):170-7. doi: 10.1097/01. SLA.0000081085.98792.3d.

12. Pearce L, Bunni J, McCarthy K, Hewitt J. Surgery in the older person: training needs for the provision of multidisciplinary care. Ann $R$ Coll Surg Engl. 2016;98(6):367-70. doi: 10.1308/rcsann.2016.0180.

13. Mathus-Vliegen EM. Prevalence, pathophysiology, health consequences and treatment options of obesity in the elderly: a guideline. Obes Facts. 2012;5(3):460-83. doi: $10.1159 / 000341193$.
14. Santos VR, Gomes IC, Bueno DR, Destro Christofaro DG, Freitas IF, Gobbo LA. Obesity, sarcopenia, sarcopenic obesity and reduced mobility in Brazilian older people aged 80 years and over. Einstein (São Paulo). 2017;15(4):43540. doi: 10.1590/S1679-45082017A04058.

15. Hyun S, Li X, Vermillion B. Body mass index and pressure ulcers: improved predictability of pressure ulcers in intensive care patients. Am J Crit Care. 2014;23(6):494501. doi: $10.4037 / a j c c 2014535$.

16. Gebhart A, Young MT, Nguyen NT. Bariatric surgery in the elderly: 2009-2013. Surg Obes Relat Dis. 2015;11(2):3938. doi: 10.1016/j.soard.2014.04.014.

17. Quebbemann B, Engstrom D, Siegfried T, Garner K, Dallal R. Bariatric surgery in patients older than 65 years is safe and effective. Surg Obes Relat Dis. 2005;1(4):389-93. doi: 10.1016/j.soard.2005.05.003.

18. Porter Starr KN, McDonald SR, Weider JA, Bales CW. Challenges in the management of geriatric obesity in high risk populations. Nutrients. 2016;8(5). doi: 10.3390/ nu8050262.

19. Sugerman HJ, DeMaria EJ, Kellum JM, Sugerman EL, Meador JG, Wolfe LG. Effects of bariatric surgery in older patients. Ann Surg. 2004;240(2):243-7. doi: 10.1097/01. sla.0000133361.68436.da.

20. Spaniolas K, Trus TL, Adrales GL, Quigley MT, Pories WJ, Laycock WS. Early morbidity and mortality of laparoscopic sleeve gastrectomy and gastric bypass in the elderly: a NSQIP analysis. Surg Obes Relat Dis. 2014;10(4):584-8. doi: 10.1016/j.soard.2014.02.010.

21. Yoon J, Shermann J, Argiroff A, Chin E, Herron D, Inabnet W, Kini S, Nguyen S. Laparoscopic sleeve gastrectomy and gastric bypass for the aging population. Obes Surg. 2016;26(11):2611-5. doi: 10.1007/s11695-016-2139-7.

22. Santo MA, Pajecki D, Riccioppo D, Cleva R, Kawamoto F, Cecconello I Early complications in bariatric surgery: incidence, diagnosis and treatment. Arq Gastroenterol. 2013;50(1):50-5. doi: 10.1590/s000428032013000100010.

23. Trieu HT, Gonzalvo JP, Szomsteins S, Rosenthal R. Safety and outcomes of laparoscopic gastric bypass surgery in patients 60 years of age and older. Surg Obes Relat Dis. 2007;3(3):383-6. doi: 10.1016/j.soard.2006.12.011.

24. Pajecki D, Santo MA, Dametto H, Morita F, Riccioppo D, Cleva RD, Cecconelo I. Bariatric surgery in the elderly: results of a mean follow-up of five years. $A B C D$ Arq Bras Cir Dig. 2015;28(Supl.1):15-8. doi: 10.1590/S0102$6720201500 \$ 100006$

25. Giordano S, Victorzon M. Bariatric surgery in elderly patients: a systematic review. Clin Interv Aging. 2015;10:1627-35. doi: 10.2147/CIA.S70313.

26. Dorman RB, Abraham AA, Al-Refaie WB, Parsons HM, Ikramuddin $S$, Habermann EB. Bariatric surgery outcomes in the elderly: an ACS NSQIP study. J Gastrointest Surg. 2012;16(1):35-44. doi: 10.1007/s11605-011-1749-6.

27. Robert M, Pasquer A, Espalieu P, Laville M, Gouillat C, Disse E. Gastric bypass for obesity in the elderly: is it as appropriate as for young and middle-aged populations? Obes Surg. 2014;24(10):1662-9. doi: 10.1007/s11695014-1247-5. 
28. Zaveri H, Surve A, Cottam D, Summerhays C, Cottam A, Richards C, Belnap LG, Medlin W. A comparison of outcomes of bariatric surgery in patient greater than 70 with 18 month of follow up. SpringerPlus. 2016;5(1):1740. doi: 10.1186/s40064-016-3392-x.

29. Huang CK, Garg A, Kuao HC, Chang PC, Hsin M. Bariatric surgery in old age: a comparative study of laparoscopic Roux-en-Y gastric bypass and sleeve gastrectomy in an Asia centre of excellence. J Biomed Res. 2015;29(2):11824. doi: 10.7555/JBR.29.20140108.

30. Abbas M, Cumella L, Zhang Y, Choi J, Vemulapalli P, Melvin WS, Camacho D. Outcomes of laparoscopic sleeve gastrectomy and Roux-en-Y gastric bypass in patients older than 60. Obes Surg. 2015;25(12):2251-6.; doi: 10.1007/ s11695-015-1712-9.

31. Gray KD, Moore MD, Bellorin O, Abelson JS, Dakin G, Zarnegar R, Pomp A, Afaneh C. Increased metabolic benefit for obese, elderly patients undergoing Roux-
en-Y gastric bypass vs sleeve gastrectomy. Obes Surg. 2018;28(3):636-42. doi: 10.1007/s11695-017-2904-2.

32. Thereaux J, Poitou C, Barsamian C, Oppert JM, Czernichow S, Bouillot JL. Midterm outcomes of gastric bypass for elderly (aged $\geq 60 \mathrm{yr}$ ) patients: a comparative study. Surg Obes Relat Dis. 2015;11(4):836-41. doi: 10.1016/j.soard.2014.10.022.

33. Ramirez A, Roy M, Hidalgo JE, Szomstein S, Rosenthal RJ. Outcomes of bariatric surgery in patients $>70$ years old. Surg Obes Relat Dis. 2012;8(4):458-62. doi: 10.1016/j. soard.2012.04.001.

34. Pajecki D, Santo MA, Kanagi AL, Riccioppo D, Cleva RD, Cecconello I. Functional assessment of older obese patients candidates for bariatric surgery. Arq Gastroenterol. 2014;51(1):25-8. doi: 10.1590/s0004-28032014000100006.

35. Nelson LG, Lopez PP, Haines K, Stefan B, Martin T, Gonzalez R, Byers P, Murr M. Outcomes of bariatric surgery in patients $>$ or $=65$ years. Surg Obes Relat Dis. 2006;2(3):384-8. doi: 10.1016/j.soard.2006.02.012.

\section{Correspondence:}

Jaques Waisberg

Avenida Ibirapuera 981/20 andar (CEDEP)

04029-000 São Paulo - SP Brasil

Tel.: (55 11)98256-0018

jaqueswaisberg@uol.com.br

Received: Feb 05, 2020

Reviewed: Apr 03, 2020

Accepted: May 02, 2020

\section{Conflict of interest: none \\ Financial source: none}

This is an Open Access article distributed under the terms of the Creative Commons Attribution License, which permits unrestricted use, distribution,

and reproduction in any medium, provided the original work is properly cited.

${ }^{1}$ Research performed at Department of Surgery, Gastrointestinal Surgery Division, Hospital do Servidor Público Estadual (IAMSPE), Sao Paulo-SP, Brazil. 